\title{
USO DO APLICATIVO SPRING NO AUXÍLIO À GESTÃO FUNDIÁRIA: O CASO DO ESTADO DO TOCANTINS
}

\author{
RODRIGO FLEURY CURADO ${ }^{1}$ \\ ELIZABETH FERREIRA ${ }^{2}$
}

\begin{abstract}
RESUMO - A concentração fundiária no Brasil ainda é muito alta, o que demanda medidas governamentais cada vez mais eficazes para melhorar essa situação. Em dezembro de 1999, o governo instituiu a Portaria INCRA/P n ${ }^{\circ} 558 / 1999$, na qual cancela todos os cadastros de imóveis com área igual ou superior a 10.000 ha, estipulando um prazo de seis meses para que os proprietários pudessem apresentar as documentações que regularizassem seus imóveis. Após 18 meses, constatou-se que a maioria das propriedades cadastradas ainda per-
\end{abstract}

manecia irregular, o que poderia caracterizar a apropriação indevida de terras "grilagem". Neste trabalho, foi utilizado o SIG: SPRING (Sistema de Processamento de Informações Georreferenciadas) para gerar mapas cadastrais de propriedades, nos municípios do Estado do Tocantins, de modo a visualizá-las espacialmente. Pode-se concluir que a visualização, consulta e a análise de dados na forma de mapas cadastrais, propiciadas pelo SPRING, podem se tornar uma ferramenta muito importante para a Reforma Agrária.

TERMOS PARA INDEXAÇÃO: SIG-SPRING, mapa cadastral, reforma agrária.

\section{THE USE OF THE SPRING SOFTWARE IN THE LAND MANAGEMENT: THE CASE OF TOCANTINS STATE}

\begin{abstract}
The concentration of large rural land properties by a few landholders is still very high in Brazil. In order to minimize this situation the government established at December 1999, the Portaria INCRA/P $\mathrm{n}^{\circ} 558 / 1999$, cancelling the whole issuing of land titles of properties with 10.000 ha or more properties. A time of six months for land titling and registration was given, but after eighteen months, the greatest number of the properties were not regularized.
\end{abstract}

This fact could appears like land unlawfull seizure. In this work it was used a GIS, software SPRING, for generate cadastral maps of rural properties at Tocantins State. The work allowed to conclude that the SPRING software is excellent in the production of cadastral maps for describing spatial information and individual parcels, as well as the fact that these maps are georeferenced. Thus SPRING could be a very important tool for the land reform.

INDEX TERMS: GIS-SPRING, cadastral maps, land reform.

\section{INTRODUÇÃO}

A situação fundiária do Brasil sempre foi caracterizada pela sua alta concentração de terras, ou seja, a maior parte das áreas ocupadas por propriedades rurais está sob domínio de poucos proprietários. Contribuindo para isso com maior ou menor gravidade, dependendo da região do País, há o problema da grilagem de terras, em que supostos proprietários aproveitam-se de documentos falsos, mas com aparência de idôneos, para apoderarem-se de terras pú- blicas ou especularem, com intuito de obterem vantagens ilícitas.

Para combater esse problema, o governo brasileiro, em dezembro de 1999, por meio do atual Ministério do Desenvolvimento Agrário, cancelou os cadastros de todas as propriedades rurais com área igual ou superior a 10.000 hectares. Essa medida ocorreu pela publicação da Portaria INCRA/P no 558/99 INCRA (1999), que tornou obrigatória a regularização de todas essas grandes propriedades, para que pudessem obter novamente o CCIR (Certificado de Cadastro de Imóvel Rural).

1. Engenheiro Agrônomo INCRA - Instituto Nacional de Colonização e Reforma Agrária. Mestre em Solos e Nutrição de Plantas - UFLA

2. Engenheiro Agrícola, DSc., Professora do Departamento de Engenharia da UNIVERSIDADE FEDERAL DE LAVRAS/UFLA - Caixa Postal 37 - 37200-000 - Lavras, MG. 
O CCIR é um documento fornecido pelo INCRA (Instituto Nacional de Colonização e Reforma Agrária) aos proprietários de imóveis rurais cadastrados no Sistema Nacional de Cadastro Rural - SNCR. Sem o CCIR, não há como negociar o imóvel ou praticar diversos atos que modifiquem a sua destinação, tamanho, domínio, etc. e ainda impossibilita empréstimos ou crédito rural junto às instituições bancárias (INCRA, 2002).

Diante de tais exigências, todos os proprietários que tinham como comprovar a legalidade de seus imóveis, apresentando as documentações necessárias dentro do prazo de seis meses estipulado pelo governo, não foram penalizados. Esse prazo foi até adiado para que eles não fossem prejudicados com o atraso de documentações que dependiam dos Cartórios de Registro de Imóveis. Mesmo assim, os proprietários que não atenderam às normas legais permaneceram com seus cadastros cancelados, de forma que, em maio de 2001, dezoito meses após a publicação da portaria, pôde-se constatar que a quantidade de imóveis em situação irregular ainda era bastante alta.

Das 3.065 propriedades rurais que foram cadastradas no Brasil, o que correspondeu a 93 milhões de hectares, 1.335 não tiveram sua documentação apresentada até maio de 2001, ou seja, cerca de 40,6 milhões de hectares. No Estado do Tocantins, onde estavam cadastrados 117 imóveis, o equivalente a 3.351 .987 hectares de terras, 94 imóveis não tiveram sua documentação apresentada, o que representou 7,3\% da área total cadastrada no País (MDA, 2001).

Os imóveis abrangidos pela portaria 558/99 e situados no Tocantins foram cadastrados em um Sistema de Informações Geográficas (SIG); no caso, o SPRING (Sistema de Processamento de Informações Georreferenciadas, desenvolvido pelo INPE - Instituto Nacional de Pesquisas Espaciais).

Sistemas de informações geográficas são ferramentas que permitem armazenar, analisar, recuperar, manipular e manejar grandes quantidades de dados espaciais, Calijuri et al. (1998). Um sistema de informação geográfica (SIG) se destaca pela sua utilidade como ferramenta para produção de mapas, como suporte para análise espacial de fenômenos e como um banco de dados geográficos (CÂMARA e MEDEIROS, 1998b).

O mapa cadastral representa cada elemento como um objeto geográfico, possuindo atributos e podendo estar associado a várias representações gráficas. Como exemplo, os lotes de uma cidade são elementos do espaço geográfico que possuem atributos, tais como nome do dono, a localização, o valor venal, etc. (Câmara e Medeiros, 1998a). Os mapas cadastrais digitais, em substituição aos mapas analógicos tradicionais, podem ser exibidos e impressos em diferentes escalas, projeções e cores, mas é, sobretudo, uma ferramenta analítica. Sua maior vantagem é a possibilidade de descrever as relações espaciais entre as suas feições (CICHOCINSK, 1999).

Catita e Catalão (1998) elaboraram um banco de dados em SIG confeccionando mapas cadastrais de parcelas agrícolas, o que vem colaborando nas ações governamentais de apoio a gestão, controle e ajudas comunitárias do INGA (Instituto Nacional de Intervenção e Garantia Agrícola) em Portugal.

Conduziu-se este trabalho com o objetivo de mostrar a possibilidade do uso do aplicativo SPRING como ferramenta de auxílio à gestão dos imóveis rurais, ante as novas leis que modernizam o sistema de registro de terras no Brasil, ao disponibilizar mapas cadastrais que possibilitam a consulta e a análise de seus dados de forma espacial, melhorando o entendimento dos mesmos.

\section{MATERIAL E MÉTODOS}

\section{Área de Estudo}

O Tocantins é um Estado com área superficial de $278.420,7 \mathrm{~km}^{2}$, situado na Região Norte do Brasil, com seus limites definidos pelas seguintes coordenadas geográficas: Long1: $51^{\circ} 25^{\prime} 57^{\prime \prime}$ oeste; Long2: $45^{\circ} 0$ ' 5 " oeste; Lat1: $13^{\circ} 49^{\prime} 50^{\prime \prime}$ sul e Lat2: $4^{\circ} 43^{\prime} 48^{\prime \prime}$ sul. Esse Estado conta com uma população de 1.048.642 habitantes e possui 139 municípios, sendo Palmas a capital. IBGE (2002)

O clima predominante é o Aw, segundo classificação de Köppen. O índice pluviométrico apresenta precipitação média mínima anual de 1.200 mm e média máxima de $1.700 \mathrm{~mm}$. A temperatura média mínima anual é de $23^{\circ} \mathrm{C}$ e a média máxima é de $26^{\circ} \mathrm{C}$. A umidade relativa varia entre uma média mínima anual de $65 \%$ e média máxima de $75 \%$, PRODIAT (1982).

\section{Material utilizado para elaboração do trabalho}

- Mapas cadastrais digitais: mapa do Tocantins, projeção policônica, datum SAD69 e escala 1:2.500.000, INPE (2002) e Cartograma do Brasil, IBGE (2002);

Ciênc. agrotec., Lavras. V.27, n.5, p.1097-1104, set./out., 2003 
- Banco de dados, elaborado no aplicativo Access, de Fiscalização de Latifúndio do INCRA: MCF - Mapa de controle de processos de fiscalização;

- Informática: aplicativos SPRING (versão 3.5.1), Word, Access, Excel e CorelDRAW para ambiente Windows 98.

\section{Metodologia}

Primeiramente, foi obtido da página do INPE, na Internet, o mapa cadastral do Estado do Tocantins contendo as divisões de municípios com alguns de seus dados (22 atributos), relacionados em uma tabela denominada "Municípios". Em seguida, os dados foram importados para o SPRING criando-se um plano de informação cadastral para inserção do mapa já associado à tabela mencionada, conforme Paiva et al. (2001). Na Figura 1, observa-se o resultado dessa importação.

Os dados das propriedades, com área igual ou superior a 10.000 ha, cadastrados no MCF-INCRA, foram inseridos no SPRING, onde foi gerada outra tabela denominada "Tab-Propriedades" contendo os seguintes atributos: Código da Propriedade, Nome da Propriedade, Nome do Proprietário, Área em hectares, Município a que pertence a propriedade e Situação Cadastral (Regular, Pendência e Cancelado - para o mês de maio de 2001).
Para que os dados dessa tabela pudessem ser disponibilizados ou visualizados, criou-se outro plano de informação da categoria cadastral denominado "Propriedades rurais", no qual foram digitalizados 117 pontos representando essas propriedades dentro de seus respectivos municípios. Em seguida, cada ponto foi selecionado e relacionado com os dados da propriedade que ele representa (da tabela "Tab-Propriedades"), formando-se, assim, o mapa cadastral de propriedades rurais.

Deve-se ressaltar que os mapas cadastrais dos imóveis abrangidos pela portaria 558/99, pertencentes ao INCRA, foram apresentados em escala apropriada, sem fins de fiscalização, bem como os atributos referentes ao nome de proprietário e nome do imóvel, da tabela "Tab-Propriedades", foram ocultados, de forma a preservar a identidade dos declarantes (quem preenche o cadastro).

\section{RESULTADOS E DISCUSSÃO}

As propriedades abrangidas pela portaria 558/99 e cadastradas no INCRA de Tocantins estão localizadas em 45 dos 139 municípios existentes no Estado. Os municípios, por sua vez, estão organizados em 8 microrregiões geográficas (Figura 3B). Na Tabela 1 encontra-se a distribuição das propriedades e das áreas cadastradas nessas microrregiões.

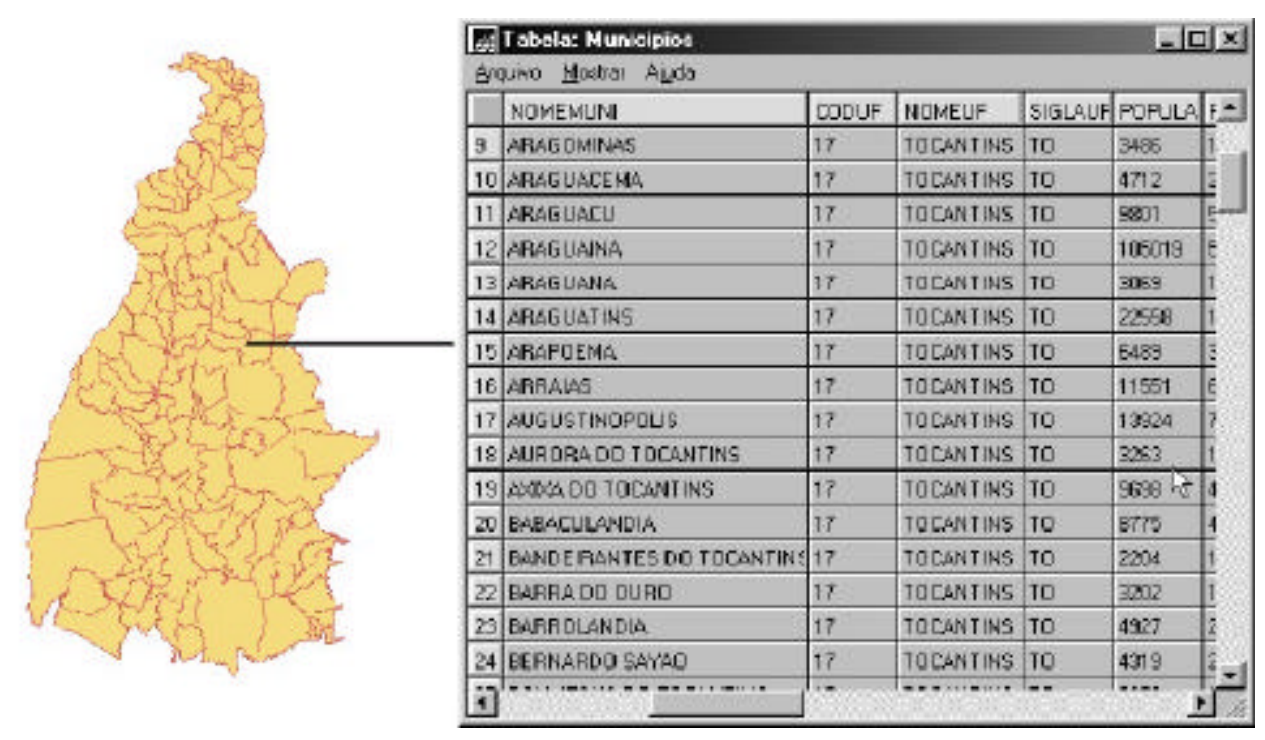

FIGURA 1 - Mapa cadastral do Estado do Tocantins. 
As 117 propriedades cadastradas estão distribuídas principalmente em 4 microrregiões: Araguaína, Rio Formoso, Jalapão e Miracema, e dessas, a primeira concentra a maior parte dos imóveis, 39,3\%. As áreas desses imóveis ou latifúndios, se somadas, representam 3.351.987,29ha. Essa área total pode ser distribuída dentro de cada microrregião, conforme mostra o gráfico da Figura 2.

Observa-se que a microrregião Bico do Papagaio - MRG2, apesar de possuir somente 3 imóveis, responde por $18,2 \%$ da área total dos imóveis cadastrados, só perdendo para a MRG1: Araguaina, com 35,7\%. Esse fato, que será mais detalhado adiante, se deve à existência, na MRG2, de uma propriedade cadastrada com área de 504.700 ha.

Dos 117 imóveis, 23 tiveram sua documentação apresentada, a fim de se obter a regularização de seus cadastros. Mesmo assim, somente 12 desses imóveis tiveram seus cadastros regularizados até maio de 2001. A Figura 3A mostra a distribuição espacial desses imóveis de situação regular no Estado.

TABELA 1 - Quantidade de imóveis e áreas, em hectares e porcentagem, nas microrregiões geográficas do Tocantins em 2001.

\begin{tabular}{llrrrr}
\hline & $\begin{array}{c}\text { Microrregião } \\
\text { geográfica }\end{array}$ & $\begin{array}{c}\text { Imóveis } \\
\left(\mathbf{n}^{\mathbf{0}}\right)\end{array}$ & $\begin{array}{c}\text { Imóveis } \\
(\boldsymbol{\%})\end{array}$ & $\begin{array}{c}\text { Área } \\
(\mathbf{h a})\end{array}$ & \begin{tabular}{c}
\multicolumn{1}{c}{ Área } \\
$(\boldsymbol{\%})$
\end{tabular} \\
\hline MRG1 & Araguaína & 46 & 39,3 & $1.196 .247,90$ & 35,7 \\
MRG2 & Bico do Papagaio & 3 & 2,6 & $608.676,30$ & 18,2 \\
MRG3 & Dianópolis & 14 & 12,0 & $285.480,90$ & 8,5 \\
MRG4 & Gurupi & 4 & 3,4 & $135.739,70$ & 4,0 \\
MRG5 & Jalapão & 15 & 12,8 & $317.893,60$ & 9,5 \\
MRG6 & Miracema & 13 & 11,1 & $288.771,60$ & 8,6 \\
MRG7 & Porto Nacional & 2 & 1,7 & $58.208,30$ & 1,7 \\
MRG8 & Rio Formoso & 20 & 17,1 & $460.969,00$ & 13,8 \\
\hline & Total & 117 & 100,0 & $3.351 .987,29$ & 100,0 \\
\hline
\end{tabular}

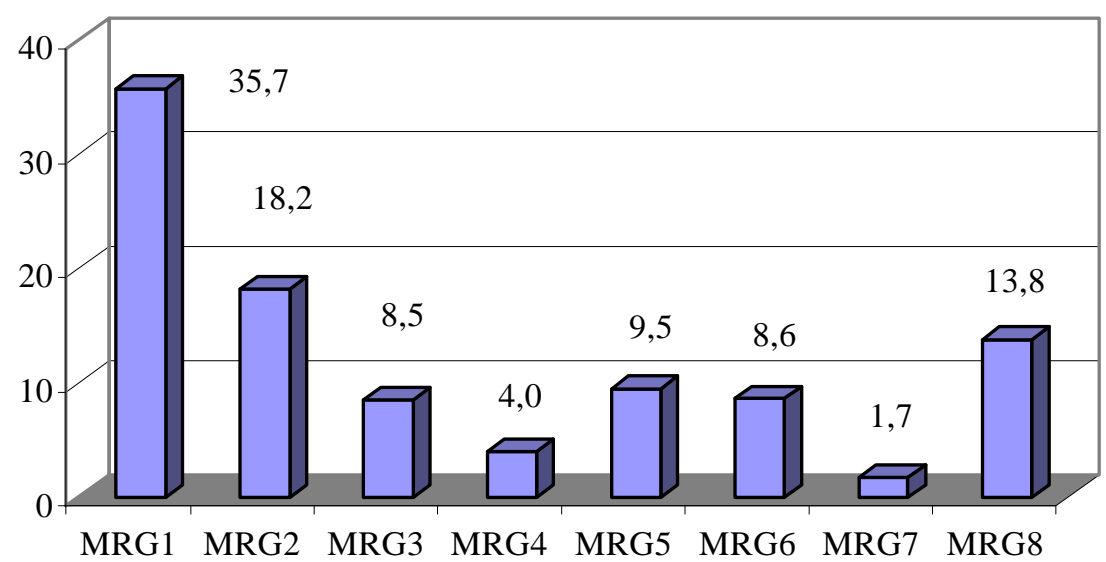

FIGURA 2 - Distribuição, em porcentagem, da área total dos imóveis cadastrados por microrregiões geográficas do Tocantins em 2001.

Ciênc. agrotec., Lavras. V.27, n.5, p.1097-1104, set./out., 2003 
Na Tabela 2 está relacionada a distribuição dos 117 imóveis e suas respectivas áreas em função da sua situação cadastral em maio de 2001.

Observa-se que a área total dos imóveis regularizados correspondeu a 5,9\% do total de áreas cadastradas. Se considerados os 23 imóveis (12 regulares e 11 pendentes) que tiveram sua documentação entregue para análise, então, 94 imóveis permaneceram com seus cadastros cancelados, o que representou $88,9 \%$ da área total de latifúndios.

Informações recebidas do INCRA-TO dão conta de que, até abril de 2002, foram 25 os imóveis efetivamente regularizados, ou seja, a situação fundiária mostrou uma tendência para configuração em torno dos números apresentados, o que pode significar o cancelamento e expurgo definitivos do cadastro do INCRA em Tocantins de cerca de $78 \%$ dos latifúndios.
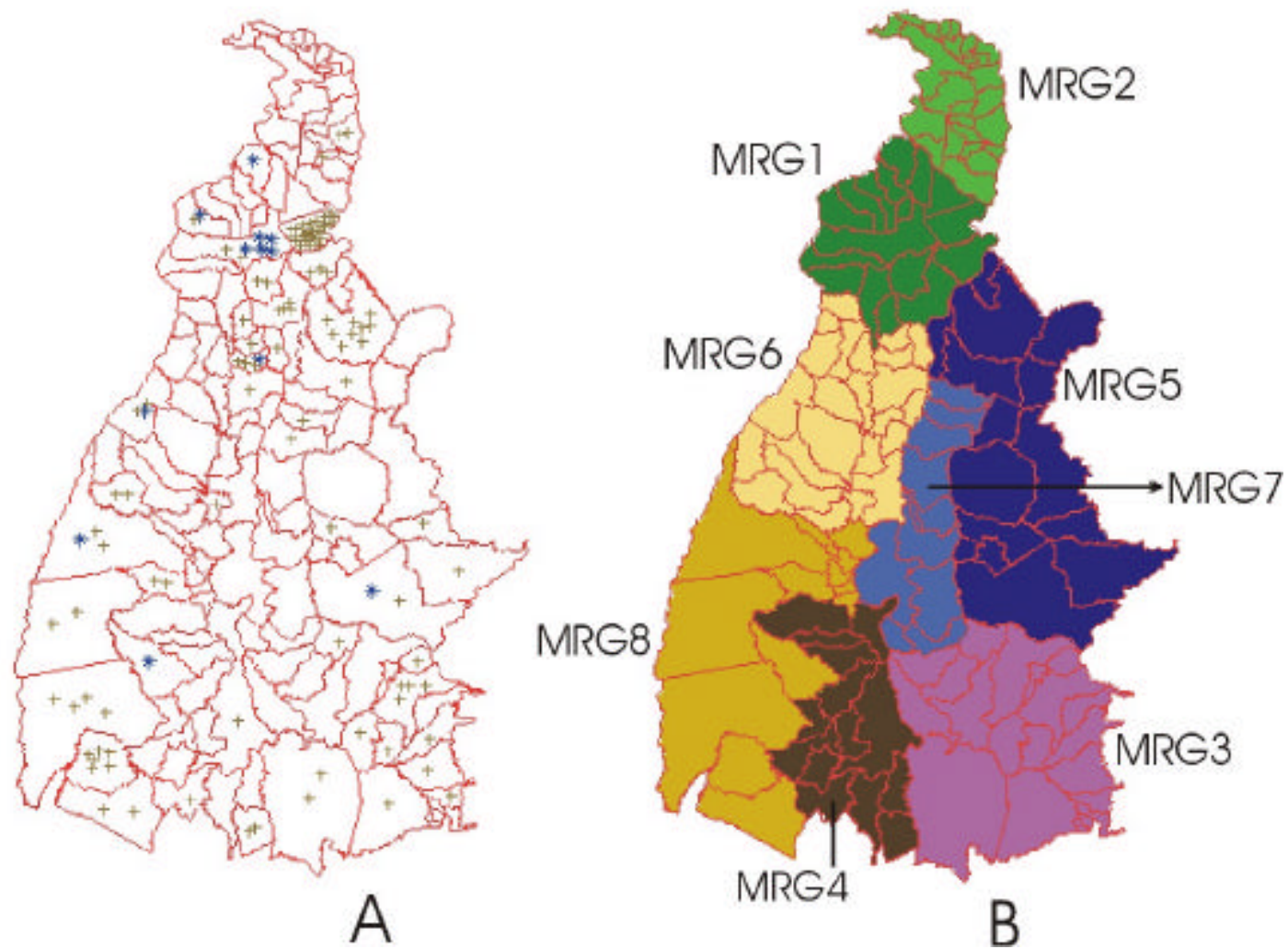

FIGURA 3 - Distribuição espacial dos imóveis regularizados [asteriscos azuis (A) e microrregiões geográficas do Tocantins (B)], ano de 2001.

TABELA 2 - Quantitativo de imóveis e áreas, em hectares e porcentagem, em função da situação cadastral em 2001.

\begin{tabular}{lcccc}
\hline Situação Cadastral & Imóveis $\left(\mathbf{n}^{\mathbf{0}}\right)$ & Imóveis $(\boldsymbol{\%})$ & Área $(\mathbf{h a})$ & Área $(\%)$ \\
\hline regular & 12 & 10,3 & $196.368,10$ & 5,9 \\
pendência & 11 & 9,4 & $174.468,30$ & 5,2 \\
cancelado & 94 & 80,3 & $2.981 .150,89$ & 88,9 \\
\hline Total & 117 & 100,0 & $3.351 .987,29$ & 100,0 \\
\hline
\end{tabular}

Ciênc. agrotec., Lavras. V.27, n.5, p.1097-1104, set./out., 2003 
Analisando-se mais pontualmente essa situação fundiária irregular, e que antes das medidas empreendidas pelo governo permanecia de certa forma oculta, serão citados alguns dados interessantes relacionados a dois municípios.

Um deles é Babaçulândia, situada na microrregião denominada Araguaína, composta de 17 municípios e com área territorial de $26.475,5937 \mathrm{~km}^{2}$. Dos 46 imóveis cadastrados nessa microrregião, 26 estão em Babaçulândia e respondem por uma área de 851.343,1963 ha, bem maior que a área do município, que é de 190.800 ha. Na Tabela 3 relacionam-se alguns dados de 15 dos 26 imóveis cancelados.

Outro caso é o do município de Tocantinópolis, da microrregião denominada Bico do Papagaio, onde estão cadastradas somente duas fazendas; uma delas, porém, com área de 504.700 ha, é mais que quatro vezes e meia a área do próprio município, 107.713,10 ha. Essa fazenda é a maior que o INCRA notificou no Es- tado do Tocantins e uma das maiores do País MDA (1999).

Pode-se fazer também operações estatísticas e outras tantas consultas nesses mapas cadastrais, dependendo, obviamente, do interesse do usuário. A consulta espacial, porém, merece destaque, pois só pode ser implementada em banco de dados geográficos.

A consulta espacial é um recurso disponível no aplicativo SPRING pela geração de mapas cadastrais georreferenciados. Ela usa o recurso da topologia, ou seja, o sistema reconhece "vizinhança" ou adjacência entre os polígonos cadastrados, permitindo, assim, a formulação de perguntas que um banco de dados convencional não responderia INPE (2001). Um exemplo de consulta, cujo resultado se vê na Figura 4 é a seguinte: quais propriedades estão localizadas na microrregião denominada rio Formoso. Dessa forma, obtêm-se 20 imóveis com suas respectivas descrições listadas em uma tabela.

TABELA 3 - Imóveis e áreas canceladas e localizadas em Babaçulândia-TO, ano de 2001.

\begin{tabular}{cllll}
\hline $\mathbf{N}^{\mathbf{0}}$ & Código Imóvel & Área (ha) & Município & Situação Cadastral \\
\hline 1 & 906085015059 & $29.890,00$ & Babaçulândia & Cancelado \\
2 & 921017010952 & $15.640,30$ & Babaçulândia & Cancelado \\
3 & 906085009938 & $46.051,00$ & Babaçulândia & Cancelado \\
4 & 000027630870 & $12.544,00$ & Babaçulândia & Cancelado \\
5 & 000019492752 & $24.200,00$ & Babaçulândia & Cancelado \\
6 & 906085012467 & $15.972,00$ & Babaçulândia & Cancelado \\
7 & 930202018724 & $29.040,00$ & Babaçulândia & Cancelado \\
8 & 906085017205 & $96.598,30$ & Babaçulândia & Cancelado \\
9 & 000019476099 & $12.544,00$ & Babaçulândia & Cancelado \\
10 & 921050000469 & $15.460,00$ & Babaçulândia & Cancelado \\
11 & 923109102342 & $12.100,00$ & Babaçulândia & Cancelado \\
12 & 921084012203 & $19.380,00$ & Babaçulândia & Cancelado \\
13 & 921114025453 & $72.600,00$ & Babaçulândia & Cancelado \\
14 & 000019474819 & $14.520,00$ & Babaçulândia & Cancelado \\
\hline
\end{tabular}

Ciênc. agrotec., Lavras. V.27, n.5, p.1097-1104, set./out., 2003 


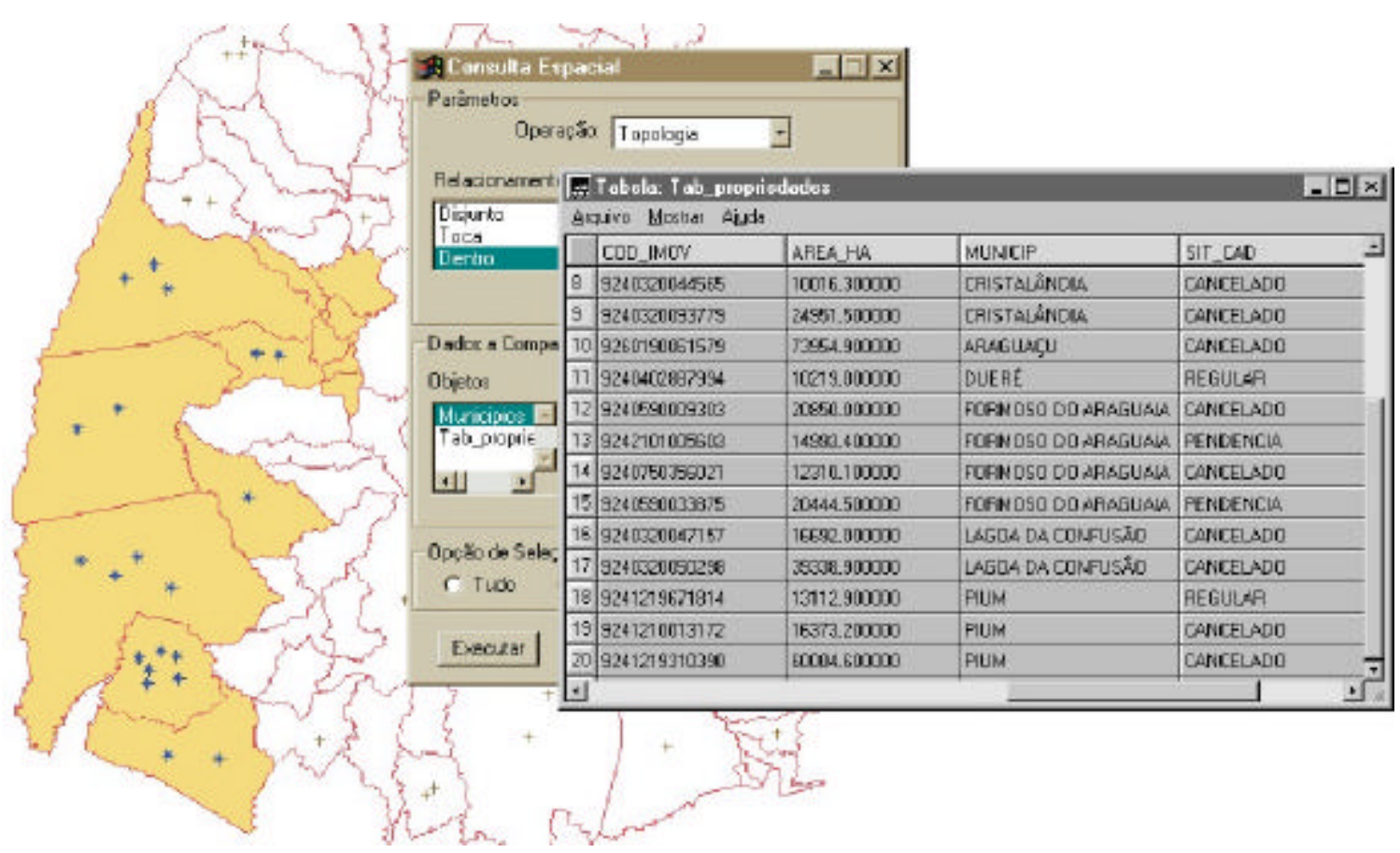

FIGURA 4 - Imóveis, abrangidos pela portaria 558/99, da microrregião Rio Formoso-TO.

\section{CONSIDERAÇÕES FINAIS}

As mudanças que vem sendo implementadas na legislação, mais a adoção das medidas de cancelamento cadastral para imóveis menores que 10.000 hectares, sendo obrigatório o georreferenciamento dos mesmos, devem promover a expansão do cadastro já existente, bem como a criação de uma malha fundiária digital, não só no Estado do Tocantins, mas em todo o País. É o caso da publicação da portaria $n^{\circ} 596 / 2001$, INCRA (2001), que torna obrigatória a regularização das propriedades com 5 mil hectares até 9.999 ha, expandindo mais ainda o controle sobre os imóveis cadastrados no País.

O governo também conseguiu aprovar a lei 10.267 (BRASIL, 2001), que criou o Sistema Público de Registro de Terras, o qual instituiu o Cadastro Nacional de Imóveis Rurais - CNIR. Dessa forma, o cadastro dos imóveis rurais passa a ser único e possibilitará o cruzamento de informações entre as Instituições Públicas interessadas (INCRA, Institutos de Terras Estaduais, Receita Federal, Ibama, etc...) e Cartórios de Registros de Imóveis. Essas medidas dificultam a fraude, não prescindindo, porém, da fiscalização para que se comprove a veracidade das informações declaradas.
Diante dos números apresentados, fica evidente a necessidade de combater a geração de cadastro de imóveis inexistentes ou a "grilagem" de terras, o que traria benefícios imediatos às instituições que lidam com documentação de terras, como cartórios, bancos e órgãos governamentais relacionados com a questão agrária.

Espera-se uma utilização maior de SIGs para auxiliar na gestão da malha fundiária digital que vêm sendo gerada, pois, além da ampliação do número de imóveis que deverão se adequar às novas normas, a manutenção do controle desses dados que mudam constantemente exige certamente melhores ferramentas de auxílio na compreensão dos mesmos. O SPRING mostrou ser adequado e útil, disponibilizando dados na forma de mapas cadastrais.

No Tocantins, a situação fundiária revelou-se extremamente especulativa no caso dos imóveis a partir de dez mil hectares.

Com as medidas empreendidas pelo governo, espera-se não só a melhoria da situação fundiária e dos índices relacionados no Estado do Tocantins, mas também uma melhor gestão das informações cadastrais fornecidas pelos proprietários e, conseqüentemente, da reforma agrária. 


\section{REFERÊNCIAS BIBLIOGRÁFICAS}

BRASIL. Lei 10.267, 28 ago. 2001. Lei de criação do Sistema Público de Registro de Terras de 2002. Diário Oficial [da] República Federativa do Brasil, Poder Executivo, Brasília, DF, 29 ago. 2001. Disponível em: <http://www.incra.gov.br/_htm/serveinf/_htm/legislaca o/lei/lei.htm>. Acesso em: 06 nov. 2002.

CALIJURI, M. L.; MEIRA, A. D.; PRUSKI, F. F. Geoprocessamento aplicado aos recursos hídricos. In: CONGRESSO BRASILEIRO DE ENGENHARIA AGRÍCOLA, 17., 1998, Poços de Caldas. Anais... Poços de Caldas: [s.n.], 1998.

CÂMARA, G.; MEDEIROS, J. S. de. Mapas e suas representações computacionais. In: ASSAD, E. A.; SANO, E. E. Sistemas de informações geográficas: aplicações na agricultura. Brasília: EMBRAPA-CPAC, 1998a. p. 13-29.

CÂMARA, G.; MEDEIROS, J. S. de. Princípios básicos em geoprocessamento. In: ASSAD, E. A.; SANO, E. E. Sistemas de informações geográficas: aplicações na agricultura. Brasília: EMBRAPA-CPAC, 1998b. p. 3-11.

CATITA, C. M.; CATALÃO, J. C. Implementação do sistema integrado de gestão e controle em Portugal. Revista Brasileira de Cartografia, Rio de Janeiro, v. 49, p. 14-26, maio 1998.

CICHOCINSKI, P. Digital cadastral maps in land information systems. LIBER Quartely, The Journal of European Research Libraries, [S.1.], v. 9, n. 2, 1999. Disponível em: <http://www.kb.nl/infolev/liber/articles/ cicho11.htm>. Acesso em: 09 abr. 2002.

INSTITUTO BRASILEIRO DE GEOGRAFIA E ESTATÍSTICA. Mapa do Brasil: cartograma. 2002. Disponível em: <www.ibge.net/home/geografia/cartogramas/ctb.html>. Acesso em: 09 abr. 2002.
INSTITUTO NACIONAL DE COLONIZAÇÃO E REFORMA AGRÁRIA. Portaria INCRA/P 558/1999. 1999. Disponível em: <http://www.incra.gov.br/estrut/ pj/portaria.htm>. Acesso em: 07 abr. 2002.

INSTITUTO NACIONAL DE COLONIZAÇÃO E REFORMA AGRÁRIA. Portaria INCRA/P 596/2001. 2001. Disponível em: <http://www.incra.gov.br/estrut/ pj/portaria.htm>. Acesso em: 07 abr. 2002.

INSTITUTO NACIONAL DE COLONIZAÇÃO E REFORMA AGRÁRIA. Certificado de cadastro de imóvel rural. Disponível em: <www.incra.gov.br/ estrut/snda/cad/certif.htm>. Acesso em: 10 maio 2002.

INSTITUTO NACIONAL DE PESQUISAS ESPACIAIS. Banco de dados geográficos. São José dos Campos, 2001. 37 p.

INSTITUTO NACIONAL DE PESQUISAS ESPACIAIS. Mapa dos Estados brasileiros com informações dos municípios. 2002. Disponível em: $<$ http://www.dpi.inpe.br/spring/portugues/mapaspr.htm 1>. Acesso em: 07 abr. 2002.

MINISTÉRIO DO DESENVOLVIMENTO AGRÁRIO. Livro branco da grilagem de terras. 1999. Disponível em: <http://www.desenvolvimentoagrario.gov. br/espaco/pubs/_down/grilagem.zip.htm>. Acesso em: 07 abr. 2002.

MINISTÉRIO DO DESENVOLVIMENTO AGRÁRIO. Balanço da reforma agrária. 2001. Disponível em: <www.desenvolvimentoagrario.gov.br/ministerio/ balanço1.htm>. Acesso em: 07 abr. 2002.

PAIVA, J. A.; LOPES, E. S. S.; YAMAGUCHI, F. Y. Banco de dados geográficos: tutorial: exercícios práticos. São José dos Campos: DPI-INPE, 2001.

PROJETO de Desenvolvimento Integrado da Bacia do Araguaia - Tocantins. Brasília: PRODIAT, 1982. 